\title{
The Janus-Faced Nature of the $\mathrm{C}_{2} \mathrm{~B}$ Domain Is Fundamental for Synaptotagmin-1 Function
}

\author{
Mingshan Xue ${ }^{1,{ }^{*}}$, Cong Ma ${ }^{2,3,{ }^{*}, \text { Timothy K. Craig }}{ }^{2,3}$, Christian Rosenmund ${ }^{1,4, \dagger}$, and Josep \\ Rizo $2,3, \dagger$ \\ ${ }^{1}$ Department of Neuroscience, Baylor College of Medicine, One Baylor Plaza, Houston, Texas \\ 77030, USA \\ ${ }^{4}$ Department of Molecular and Human Genetics, Baylor College of Medicine, One Baylor Plaza, \\ Houston, Texas 77030, USA \\ ${ }^{2}$ Department of Biochemistry, University of Texas Southwestern Medical Center, Dallas, 6000 \\ Harry Hines Boulevard, Dallas, Texas 75390, USA \\ ${ }^{3}$ Department of Pharmacology, University of Texas Southwestern Medical Center, Dallas, 6000 \\ Harry Hines Boulevard, Dallas, Texas 75390, USA
}

\section{Abstract}

\begin{abstract}
Synaptotagmin-1 functions as a $\mathrm{Ca}^{2+}$ sensor in neurotransmitter release, and was proposed to act on both the synaptic vesicle and plasma membranes through interactions involving the $\mathrm{Ca}^{2+}$ binding top loops of its $\mathrm{C}_{2}$ domains and the $\mathrm{Ca}^{2+}$-independent bottom face of the $\mathrm{C}_{2} \mathrm{~B}$ domain. However, the functional importance of the $\mathrm{C}_{2} \mathrm{~B}$ domain bottom face is unclear. We now show that mutating two conserved arginines at the $\mathrm{C}_{2} \mathrm{~B}$ domain bottom face practically abolishes synchronous release in hippocampal neurons. Reconstitution experiments reveal that $\mathrm{Ca}^{2+}$ synaptotagmin-1 can dramatically stimulate the rate of SNARE-dependent lipid mixing/fusion and that the two-arginine mutation strongly impairs this activity. These results demonstrate that synaptotagmin-1 function depends critically on the bottom face of the $\mathrm{C}_{2} \mathrm{~B}$ domain and strongly support the notion that synaptotagmin-1 triggers membrane fusion and neurotransmitter release by bringing the vesicle and plasma membranes together, much like the SNAREs do but in a $\mathrm{Ca}^{2+}$ dependent manner.
\end{abstract}

The $\mathrm{Ca}^{2+}$-triggered release of neurotransmitters by synaptic vesicle exocytosis is an exquisitely regulated process, exhibiting a fast, synchronous component that emerges in less than $0.5 \mathrm{~ms}$ upon $\mathrm{Ca}^{2+}$ influx, and a slower, asynchronous component1. Extensive evidence has shown that the synaptic vesicle protein synaptotagmin- 1 acts as a $\mathrm{Ca}^{2+}$ sensor in synchronous release [reviewed in 1-3]. Most of the cytoplasmic region of synaptotagmin-1 consists of two $\mathrm{C}_{2}$ domains (called $\mathrm{C}_{2} \mathrm{~A}$ and $\mathrm{C}_{2} \mathrm{~B}$ domain), which adopt similar $\beta$-sandwich structures and bind three and two $\mathrm{Ca}^{2+}$ ions, respectively, through loops at the top of the $\beta$ -

Users may view, print, copy, and download text and data-mine the content in such documents, for the purposes of academic research, subject always to the full Conditions of use:http://www.nature.com/authors/editorial_policies/license.html\#terms

${ }^{\dagger}$ To whom correspondence should be addressed. E-mail: rosenmun@bcm.tmc.edu (C.R.); jose@arnie.swmed.edu (J.R.).

These authors contributed equally to this work. 
sandwich4-8 (Fig. 1a). These top loops also mediate $\mathrm{Ca}^{2+}$-dependent binding of both $\mathrm{C}_{2}$ domains to phospholipids8-11, and decreasing or increasing the apparent $\mathrm{Ca}^{2+}$ affinity of synaptotagmin-1 through point mutations in the $\mathrm{Ca}^{2+}$-binding loops leads to parallel changes in the $\mathrm{Ca}^{2+}$ dependence of neurotransmitter release 12, 13. In addition to establishing the $\mathrm{Ca}^{2+}$-sensing role of synaptotagmin-1 in release, these results showed that the $\mathrm{Ca}^{2+}$ dependent phospholipid binding activity of the $\mathrm{C}_{2}$ domain top loops is key for this function. Synaptotagmin-1 also binds to the neuronal soluble N-ethylmaleimide-sensitive factor attachment protein receptors (SNAREs), which play a key role in membrane fusion by forming tight SNARE complexes that bring the synaptic vesicle and plasma membranes together [reviewed in 1-3, 14, 15]. $\mathrm{Ca}^{2+}$-dependent binding of synaptotagmin-1 to SNARE complexes and phospholipids can occur simultaneously 16, 17, which likely helps to couple synaptotagmin-1 and SNARE function.

Many current models assume that synaptotagmin-1 triggers release through an action on the plasma membrane, for instance assisting in membrane fusion by inducing tension 1,3 and/or positive curvature 18. However, these models do not explain the observation that disrupting $\mathrm{Ca}^{2+}$ binding to the $\mathrm{C}_{2} \mathrm{~B}$ domain impairs release much more strongly 19, 20 than disruption of the $\mathrm{C}_{2} \mathrm{~A}$ domain $\mathrm{Ca}^{2+}$ binding sites21-23. This preponderant role of the $\mathrm{C}_{2} \mathrm{~B}$ domain in release could arise in part from a polybasic region at one side of the $\mathrm{C}_{2} \mathrm{~B}$ domain $\beta$-sandwich (Fig. 1a) that is not shared by the $\mathrm{C}_{2} \mathrm{~A}$ domain and has been implicated in multiple interactions, including SNARE complex17, 24 and phospholipid binding25. However, while the moderate impairment in release caused by mutations in this polybasic region supports its involvement in exocytosis 25,26 , it does not provide a satisfactory explanation for the dramatic difference in the functional importance of $\mathrm{Ca}^{2+}$ binding to the $\mathrm{C}_{2} \mathrm{~B}$ domain versus the $\mathrm{C}_{2} \mathrm{~A}$ domain. Another potential reason for this drastic difference was provided by the observation that the $\mathrm{C}_{2} \mathrm{~B}$ domain can induce clustering of liposomes in the presence of $\mathrm{Ca}^{2+}$, whereas the $\mathrm{C}_{2} \mathrm{~A}$ domain does not share this activity 27 . This finding led to a fundamentally different hypothesis of synaptotagmin- 1 function proposing that the $\mathrm{C}_{2} \mathrm{~B}$ domain acts not only on the plasma membrane but also on the vesicle membrane, bringing the two membranes into close proximity like SNARE complexes do, but in a $\mathrm{Ca}^{2+}$-dependent manner that confers the acute $\mathrm{Ca}^{2+}$-sensitivity of synaptic membrane fusion. In this model, the $\mathrm{Ca}^{2+}$-binding loops at the top of the $\mathrm{C}_{2} \mathrm{~B}$ domain $\beta$-sandwich bind to one membrane and basic residues at the opposite, bottom face bind to the other membrane17, 27 (Fig. 1a). However, while the crucial role of the $\mathrm{C}_{2} \mathrm{~B}$ domain $\mathrm{Ca}^{2+}$-binding region in release is well established19, 20, the functional importance of the bottom face has not been investigated.

We now report that, during electrophysiological studies designed to screen for features at the C-terminus of the $\mathrm{C}_{2} \mathrm{~B}$ domain that modulate $\mathrm{Ca}^{2+}$-triggered release, we have identified two highly conserved arginines that protrude at the bottom face of the $\mathrm{C}_{2} \mathrm{~B}$ domain (R398 and R399; Figs. 1a,b) as key residues for synaptotagmin-1 function. Mutation of these arginines almost abolishes $\mathrm{Ca}^{2+}$-triggered fast neurotransmitter release in hippocampal neurons. Further biophysical analyses showed that, in the presence of synaptotagmin-1, $\mathrm{Ca}^{2+}$ can induce a dramatic increase in the rate of lipid mixing between reconstituted SNARE proteoliposomes, and that mutating the two arginines strongly impairs this activity due to disruption of $\mathrm{C}_{2} \mathrm{~B}$ domain-membrane interactions. Our results demonstrate that the $\mathrm{Ca}^{2+}$ independent, bottom face of the synaptotagmin- $1 \mathrm{C}_{2} \mathrm{~B}$ domain plays a critical function in 
neurotransmitter release, similar in importance to the key role of the $\mathrm{Ca}^{2+}$-dependent, top face. Moreover, our data strongly support the notion that synaptotagmin-1 acts on both the vesicle and plasma membranes by bringing them together in a $\mathrm{Ca}^{2+}$-dependent manner through the Janus-faced nature of the $\mathrm{C}_{2} \mathrm{~B}$ domain.

\section{RESULTS}

\section{The two $\mathrm{C}_{2} \mathrm{~B}$ domain bottom arginines are crucial for release}

To test the functional importance of the bottom face of the synaptotagmin- $1 \mathrm{C}_{2} \mathrm{~B}$ domain, we used a synaptotagmin-1 knockout (KO)-rescue approach in autaptic hippocampal glutamatergic neurons13. In response to a single action potential, the excitatory postsynaptic current (EPSC) amplitude and charge of synaptotagmin-1 KO neurons are drastically reduced, whereas asynchronous release remains unaltered [Ref. 28; Fig. 2]. Lentiviral expression of wild type (WT) synaptotagmin-1 in KO neurons restored the diminished $\mathrm{Ca}^{2+}$ triggered synchronous release to that of WT neurons (Fig. 2 and M.X. and C.R. unpublished results). We next tested the effects of mutating Arg398 and Arg399, the two exposed, highly conserved arginines at the bottom loop between helix HA and strand $\beta 8$ of the $\mathrm{C}_{2} \mathrm{~B}$ domain (Fig.1). For this purpose, we prepared single mutants where one arginine was replaced by glutamine (R398Q and R399Q) and a double mutant (R398Q,R399Q), which preserves proper folding of the $\mathrm{C}_{2} \mathrm{~B}$ domain 27 (see also below). Lentiviral expression of these mutants in synaptotagmin-1 KO neurons led to comparable protein levels to those observed for WT synaptotagmin-1 (Supplementary Fig. 1 online), and immunocytochemistry showed that these mutants are co-localized with the synaptic vesicle marker synaptophysin-1, indicating that they are properly targeted to synapses (Supplementary Fig. 2 online). Intriguingly, the R398Q,R399Q mutation practically abolished the rescue activity of synaptotagmin-1. KO neurons rescued by this mutant showed diminished synchronous release, and the evoked EPSC amplitude, charge, and release time course resembled those of synaptotagmin-1 KO neurons (Fig. 2). Both R398Q and R399Q single mutants strongly reduced evoked EPSC amplitude and charge (Figs. 2a-c), but the release remained largely synchronous (Figs. 2a,d). These results demonstrate the critical importance of the bottom region of the $\mathrm{C}_{2} \mathrm{~B}$ domain for synaptotagmin-1 function in fast neurotransmitter release.

Synaptotagmin-1 has been implicated at multiple steps of the synaptic vesicle cycle. To pinpoint the function of the $\mathrm{C}_{2} \mathrm{~B}$ domain bottom face, we directly assessed $\mathrm{Ca}^{2+}$-triggered release efficiency by measuring the vesicular release probability $\left(P_{v r}\right)$, the fraction of fusion competent vesicles released by an action potential. This parameter is assessed by the ratio of the single EPSC charge and readily releasable vesicle pool (RRP) charge. We measured RRP from the synaptic responses induced by 4-s application of hypertonic sucrose solution29 and found no significant differences in RRP size among all the groups $(\mathrm{P}>0.05$, data not shown). Consequently, mutating either or both arginines caused more than $80 \%$ reduction of $P_{v r}$, as compared to the WT synaptotagmin-1 rescue (Fig. 3a). Consistent with the $P_{v r}$ data, mutating the arginines altered short-term plasticity of rescued KO neurons. In response to 5 consecutive action potentials delivered at $50 \mathrm{~Hz}, \mathrm{KO}$ neurons rescued by WT synaptotagmin-1 showed synaptic depression, whereas R398Q, R399Q and R398Q,R399Q all led to enhanced synaptic facilitation (Fig. 3b). In contrast to KO neurons, the 
R398Q,R399Q-rescued neurons exhibited some synchronous release after 2 or 3 stimuli, indicating that elevation of intracellular $\mathrm{Ca}^{2+}$ concentrations can slightly rescue the R398Q,R399Q phenotype (Fig. 3b). We then studied the $\mathrm{Ca}^{2+}$-dependence of transmitter release by measuring the amplitudes of the evoked synaptic responses as a function of the external $\mathrm{Ca}^{2+}$ concentrations. Fitting the data with a standard Hill equation revealed a more than 2-fold decrease in the apparent $\mathrm{Ca}^{2+}$-sensitivity of release in $\mathrm{KO}$ neurons rescued with single (R398Q or R399Q) or double (R398Q,R399Q) arginine mutants as compared to KO neurons rescued with WT synaptotagmin-1 (Fig. 3c).

\section{The two-arginine mutation impairs membrane interactions}

Our electrophysiological results demonstrate that the unique bottom face of the $\mathrm{C}_{2} \mathrm{~B}$ domain plays an essential role at the $\mathrm{Ca}^{2+}$-triggering step of exocytosis, and support the proposal that binding of the $\mathrm{C}_{2} \mathrm{~B}$ domain to the vesicle and plasma membranes through the bottom face and the $\mathrm{Ca}^{2+}$-binding top loops is critical for release. However, it is also plausible that the R398Q,R399Q mutation at the bottom of the $\mathrm{C}_{2} \mathrm{~B}$ domain might have allosteric effects that impair $\mathrm{Ca}^{2+}$ binding. This possibility is unlikely because $\mathrm{Ca}^{2+}$ binding to the $\mathrm{C}_{2} \mathrm{~B}$ domain does not change the chemical shifts at the bottom face8 and was completely rule out by comparing ${ }^{1} \mathrm{H}_{-}{ }^{15} \mathrm{~N}$ HSQC spectra of WT and R398Q,R399Q-C 2 AB fragment, which showed that the mutation does not alter $\mathrm{Ca}^{2+}$ binding and does not cause substantial structural alterations in the $\mathrm{Ca}^{2+}$-binding loops or any other region of the $\mathrm{C}_{2} \mathrm{AB}$ fragment (Supplementary Fig. 3 online). The R398Q,R399Q mutation could also alter synaptotagmin-1/SNARE complex interactions. To test this possibility, we examined the ability of the $\mathrm{C}_{2} \mathrm{AB}$ fragment to displace a complexin-1 fragment from SNARE complexes anchored on supported phospholipid bilayers30, an activity that requires $\mathrm{Ca}^{2+}$-dependent phospholipid binding of the top loops of the $\mathrm{C}_{2} \mathrm{AB}$ fragment and interactions with SNARE complexes17. The R398Q,R399Q mutation did not substantially change this activity (Fig. $4 a$ ), showing that this mutation does not interfere with the $\mathrm{C}_{2} \mathrm{AB}$ fragment/SNARE complex interaction.

Based on these results, the most likely explanation for our electrophysiological data is that the inhibition of release by the R398Q,R399Q mutation arises from disruption of critical membrane interactions of the bottom face of the $\mathrm{C}_{2} \mathrm{~B}$ domain. The R398Q,R399Q mutation abolishes the ability of the synaptotagmin- $1 \mathrm{C}_{2} \mathrm{~B}$ domain to induce clustering of phospholipid vesicles in vitro27, showing that the bottom face can indeed participate in membrane interactions in vitro. However, the R398Q,R399Q mutation did not appear to impair the ability of the $\mathrm{C}_{2} \mathrm{AB}$ fragment to cluster vesicles after a 10 min incubation in 1 $\mathrm{mM} \mathrm{Ca}^{2+}$ (Ref. 27). To test the effects of this mutation under more stringent conditions, we monitored the ability of different synaptotagmin- 1 fragments to induce vesicle clustering as a function of time in the presence of $0.1 \mathrm{mM} \mathrm{Ca}^{2+}$ using dynamic light scattering (DLS). The $\mathrm{WT}_{2} \mathrm{AB}$ fragment quickly induced vesicle clustering, as manifested by the observed increase in the average particle size within the first few minutes, and $\mathrm{C}_{2} \mathrm{AB}$ fragments with mutations that disrupt $\mathrm{Ca}^{2+}$ binding to the $\mathrm{C}_{2} \mathrm{~A}$ domain $\left(\mathrm{D} 178 \mathrm{~N}^{6}\right)$ or the $\mathrm{C}_{2} \mathrm{~B}$ domain $\left(\mathrm{D} 309 \mathrm{~N}^{8}\right)$ exhibited the same clustering activity (Fig. 4b), as observed previously27. Also in agreement with previous results, the isolated $\mathrm{C}_{2} \mathrm{~B}$ domain clustered vesicles efficiently, and this activity was abolished by the D309N and the R398Q,R399Q mutations (Fig. 4b). 
Importantly, the R398Q,R399Q mutation also caused a strong impairment in the ability of the $\mathrm{C}_{2} \mathrm{AB}$ fragment to cluster vesicles under these conditions; addition of $1 \mathrm{mM} \mathrm{Ca}^{2+}$ after $500 \mathrm{~s}$ accelerated clustering by the R398Q,R399Q- $\mathrm{C}_{2} \mathrm{AB}$ fragment, leading to large clusters after $10 \mathrm{~min}$, as observed previously 27, but the kinetics of clustering was still slower in 1 $\mathrm{mM} \mathrm{Ca}^{2+}$ than for the WT $\mathrm{C}_{2} \mathrm{AB}$ fragment in $0.1 \mathrm{mM} \mathrm{Ca}^{2+}$ (Fig. 4b). Hence, the bottom face of the $\mathrm{C}_{2} \mathrm{~B}$ domain is more critical for vesicle clustering than $\mathrm{Ca}^{2+}$ binding to either the $\mathrm{C}_{2} \mathrm{~A}$ or $\mathrm{C}_{2} \mathrm{~B}$ domain. However, clustering does require $\mathrm{Ca}^{2+}$ binding to at least one $\mathrm{C}_{2}$ domain, as a double D178N,D309N mutation in the $\mathrm{C}_{2} \mathrm{AB}$ fragment completely abolished its clustering activity (Supplementary Fig. 4 online).

\section{Fast stimulation of lipid-mixing by $\mathrm{Ca}^{2+} /$ synaptotagmin-1}

To further investigate the minimal requirements for the role of the R398Q,R399Q mutation with a defined reductionist system, we turned to reconstitution experiments with SNAREcontaining proteoliposomes, in which the ability of protein components to induce lipid mixing is used as an indication of their potential roles in membrane fusion31. Early studies using a standard fluorescence dequenching assay 31 showed that the $\mathrm{Ca}^{2+}$-bound synaptotagmin-1 $\mathrm{C}_{2} \mathrm{AB}$ fragment can increase the rate of SNARE-dependent lipid mixing32. For our studies, we adopted an approach whereby SNARE complex assembly is facilitated by preincubation of the t-SNARE liposomes with a peptide containing the $\mathrm{C}$-terminal half of the synaptobrevin SNARE motif33. Incubation of equal amounts of t-SNARE and vSNARE liposomes containing 1:200 protein-to-lipid (P/L) ratios leads to very efficient and saturable lipid mixing (Supplementary Fig. 5a online), as described33. Conversion of the observed fluorescence dequenching to rounds of liposome fusion34 showed that saturation occurs at 1.16 rounds of fusion (Supplementary Fig. $5 \mathrm{~b}$ online), which suggests that fusion is quantitative under these conditions and corresponds to an increase in relative fluorescence with respect to the initial value $\left(\mathrm{F} / \mathrm{F}_{0}\right)$ of 1.52 . Since in our hands representation of lipid mixing assays using $\mathrm{F} / \mathrm{F}_{0}$, as adopted by Pobbati et al.33, yields more consistent results than conversion to rounds of fusion (likely because of variability in the maximum fluorescence observed upon detergent addition, which is used for this conversion), we used the former method to express the lipid mixing data described below (Fig. 5).

As described previously35, $\mathrm{Ca}^{2+}$ plus the $\mathrm{C}_{2} \mathrm{AB}$ fragment did not enhance lipid mixing at 1:200 P/L ratio (Fig. 5a). Since the absence of a stimulating effect of $\mathrm{Ca}^{2+} /$ synaptotagmin-1 most likely arises because the SNAREs are too active at this $\mathrm{P} / \mathrm{L}$ ratio, in all subsequent experiments we lowered the $\mathrm{P} / \mathrm{L}$ ratio to 1:500, which markedly decreased the lipid mixing efficiency of the SNAREs alone (Fig. 5a). Inclusion of $1 \mu \mathrm{M} \mathrm{C}_{2} \mathrm{AB}$ fragment in the initial reaction under these conditions did not substantially alter the lipid-mixing rate but, importantly, addition of $0.1 \mathrm{mM} \mathrm{Ca}^{2+}$ after $250 \mathrm{~s}$ led to a dramatic increase in lipid mixing (Fig. 5b). This effect was SNARE dependent, as it was inhibited by the soluble region of synaptobrevin and the $\mathrm{C}_{2} \mathrm{AB}$ fragment did not induce lipid mixing in the absence of SNAREs (Supplementary Fig. 6 online). The lipid-mixing stimulation required the $\mathrm{C}_{2} \mathrm{AB}$ fragment and was specific for $\mathrm{Ca}^{2+}$, since $1 \mathrm{mM} \mathrm{Ca}^{2+}$ without $\mathrm{C}_{2} \mathrm{AB}$ fragment or $1 \mathrm{mM}$ $\mathrm{Mg}^{2+}$ in the presence of $\mathrm{C}_{2} \mathrm{AB}$ fragment had no effect (Fig.5b). In multiple experiments (e.g. black traces in Figs. 5b,c,f), lipid mixing was saturated at values of $\mathrm{F} / \mathrm{F}_{0}$ above 1.5, which corresponds to at least one round of fusion and thus suggests that fusion is quantitative (see 
above). Although there was some variability in the lipid-mixing rates, dramatic increases in these rates (40- to 130-fold) were consistently observed upon $\mathrm{Ca}^{2+}$ addition in the presence of the $\mathrm{C}_{2} \mathrm{AB}$ fragment. Conversion to rounds of fusion34 and curve fitting yielded a rate of $0.099 \pm 0.035$ rounds of fusion per second during the initial burst upon $\mathrm{Ca}^{2+}$ addition (corresponding to a time constant $\tau$ of ca. $10 \mathrm{~s}$ ).

\section{The two-arginine mutation impairs lipid-mixing stimulation}

We next examined the effects of different mutations on the lipid-mixing enhancement caused by the $\mathrm{Ca}^{2+}$-bound $\mathrm{C}_{2} \mathrm{AB}$ fragment (Fig. 5). Quantification of stimulation activities was hindered by variability in the background lipid mixing occurring before $\mathrm{Ca}^{2+}$ addition and occasional downward baseline drifts after $\mathrm{Ca}^{2+}$ addition that may arise in part from sample precipitation (e.g. Fig. 5h). However, consistent estimates of the relative activities of the different synaptotagmin- 1 fragments were obtained by measuring the increase in $\mathrm{F} / \mathrm{F}_{0}$ after 40 seconds of $\mathrm{Ca}^{2+}$ addition (after subtracting the background of $\mathrm{Ca}^{2+}$-independent lipid mixing) and normalizing the data to the $\mathrm{F} / \mathrm{F}_{0}$ increase measured for the $\mathrm{WT}_{2} \mathrm{AB}$ fragment with the same proteoliposome preparations (Fig. 6). Remarkably, the $R 398 Q, R 399$ Q mutation in the bottom of the $\mathrm{C}_{2} \mathrm{~B}$ domain strongly impaired the ability of the $\mathrm{C}_{2} \mathrm{AB}$ fragment to stimulate lipid mixing (Fig. 5c, 6), even after adding up to $1 \mathrm{mM} \mathrm{Ca}^{2+}$ (Fig. 5d). The single R398Q and R399Q mutations also led to marked impairments of the lipid mixing, although to a lesser extent (Fig. 5c, 6). For comparison, we also tested the effects of mutations that disrupt $\mathrm{Ca}^{2+}$ binding to the $\mathrm{C}_{2} \mathrm{~A}$ or $\mathrm{C}_{2} \mathrm{~B}$ domain (D178N and D309N, respectively). Both mutations impaired lipid-mixing stimulation, but less strongly than the double R398Q,R399Q mutation (Fig. 5e, 6).

Although the effects of the single arginine mutations on lipid-mixing stimulation correlate qualitatively with their inhibitory effects on neurotransmitter release (Fig 2), the latter were much stronger. Moreover, the stronger impairment of lipid-mixing activity caused by the D178N mutation in the $\mathrm{C}_{2} \mathrm{~A}$ domain, compared to the $\mathrm{D} 309 \mathrm{~N}$ mutation in the $\mathrm{C}_{2} \mathrm{~B}$ domain, contrasts with the preponderant role of the $\mathrm{C}_{2} \mathrm{~B}$ domain in release 19-23. This discrepancy was observed previously 35 and may arise because the $\mathrm{C}_{2} \mathrm{AB}$ fragment likely binds to two apposed membranes in diverse orientations 27. Interestingly, we found that the isolated $\mathrm{C}_{2} \mathrm{~B}$ domain can partially support the $\mathrm{Ca}^{2+}$-induced lipid-mixing enhancement, whereas the isolated $\mathrm{C}_{2} \mathrm{~A}$ domain does not share this ability (Fig. 5 f, 6). Note that previous data suggesting that the $\mathrm{C}_{2} \mathrm{~B}$ domain cannot increase SNARE-mediated lipid mixing32 may arise from known difficulties in purifying the $\mathrm{C}_{2} \mathrm{~B}$ domain 36 and, indeed, we did not observe lipid-mixing stimulation when we used $\mathrm{C}_{2} \mathrm{~B}$ domain purified under less stringent conditions (Fig. 5f). Importantly, the ability of properly purified $\mathrm{C}_{2} \mathrm{~B}$ domain to support the lipidmixing enhancement was abrogated by both the R398Q,R399Q mutation and the D309N mutation that disrupts $\mathrm{Ca}^{2+}$ binding to the $\mathrm{C}_{2} \mathrm{~B}$ domain (Fig. $5 \mathrm{~g}$, 6). Even the single $\mathrm{R} 398 \mathrm{Q}$ and R399Q mutations strongly impaired lipid-mixing stimulation by the $\mathrm{C}_{2} \mathrm{~B}$ domain (Fig. $5 \mathrm{~h}, 6$ ), showing that both arginines cooperate in this activity, as they do in neurotransmitter release. Thus, our data with the isolated $\mathrm{C}_{2}$ domains correlate with the preponderant role of the $\mathrm{C}_{2} \mathrm{~B}$ domain in release and with the strong impairment of release caused by disruption of its $\mathrm{Ca}^{2+}$-binding sites or mutations in Arg398 and Arg399 [Figs. 2,3 and refs. 19, 20]. 


\section{Discussion}

Synaptotagmin-1 function is generally assumed to involve an action of the $\mathrm{Ca}^{2+}$-binding top loops of its $\mathrm{C}_{2}$ domains on the plasma membrane $1,3,18$. Through electrophysiological screens for additional functional sites on the $\mathrm{C} 2 \mathrm{~B}$ domain, we have now found that two arginines located at its bottom face are crucial for the function of synaptotagmin-1 in neurotransmitter release. These residues are also key for its ability to bring two membranes together and to stimulate SNARE-mediated lipid-mixing in vitro. These results show that synaptotagmin- 1 function depends not only on the $\mathrm{Ca}^{2+}$-binding loops but also on the $\mathrm{C}_{2} \mathrm{~B}$ domain bottom face, and strongly support the notion that synaptotagmin- 1 cooperates with the SNARE complex in triggering fast membrane fusion by binding simultaneously to the vesicle and plasma membranes (Fig. 7).

The almost complete abrogation of fast release caused by the double R398Q,R399Q mutation (Fig. 2) is remarkable. Although the functional effects of many point mutations in synaptotagmin-1 have been studied1-3, only mutations in the $\mathrm{C}_{2} \mathrm{~B}$ domain $\mathrm{Ca}^{2+}$-binding sites lead to a comparably strong impairment of release as assessed with highly sensitivity electrophysiological recordings in mammalian synapses20. Even single mutations in these arginines result in strong inhibition of release (Fig. 2), suggesting that both arginines cooperate in a critical activity. Mutation of both sites does not completely block synaptotagmin-1 function; intriguingly, the R398,R399 double mutant mimicked the synaptotagmin-1 KO phenotype at slow frequency stimulation, yet this mutant was still weakly active in triggering release, as high frequency stimulation slightly restores synchronous release, presumably due to residual activity of the bottom face of the $\mathrm{C}_{2} \mathrm{~B}$ domain.

The key role of this bottom face in release is unlikely to involve direct interactions of Arg398 and Arg399 with the SNARE complex, since the R398Q,R399Q mutation did not impair the ability of the $\mathrm{C}_{2} \mathrm{AB}$ fragment to displace a complexin-1 fragment from membrane-anchored SNARE complexes (Fig. 4a). This observation agrees well with the notion that the $\mathrm{Ca}^{2+}$ binding loops and the bottom face of the $\mathrm{C}_{2} \mathrm{~B}$ domain bind to two apposed membranes, leaving the polybasic region of $\mathrm{C}_{2} \mathrm{~B}$ domain available for binding to SNARE complexes (Fig. 7)17. Moreover, NBD fluorescence experiments showed that the $\mathrm{C}_{2} \mathrm{~B}$ domain bottom face interacts with membranes27, and the profound impairment of vesicle clustering activity caused by the R398Q,R399Q mutation (Fig. 4b) demonstrates that interactions of Arg398 and Arg399 with lipids are crucial for the ability of synaptotagmin-1 to bring two membranes together. These findings, together with our lipid mixing assays, strongly suggest that the impairment of neurotransmitter release caused by the $\mathrm{R} 398 \mathrm{Q}, \mathrm{R} 399 \mathrm{Q}$ mutation is due to disruption of critical $\mathrm{C}_{2} \mathrm{~B}$ domain-membrane interactions.

Lipid mixing assays need to be interpreted with caution, since they do not necessarily reflect physiological membrane fusion events 2 . Thus, the relevance of initial data showing that the $\mathrm{Ca}^{2+}$-bound synaptotagmin-1 $\mathrm{C}_{2} \mathrm{AB}$ fragment enhances SNARE-dependent lipid mixing32 was unclear, as the enhancement was modest (2-4 fold), the lipid mixing rates were very slow ( $\tau>30$ min32), and the effects of $\mathrm{Ca}^{2+}$-binding site mutations on lipid-mixing stimulation did not correlate well with their effects on release 35,37 . Our data show that, in 
the presence of $1 \mu \mathrm{M} \mathrm{C}_{2} \mathrm{AB}$ fragment and under our experimental conditions, $100 \mu \mathrm{M} \mathrm{Ca}^{2+}$ can induce a much more dramatic stimulation of lipid mixing ( 100-fold) and lead to much faster lipid mixing rates $(\tau \sim 10 \mathrm{~s})$, which are remarkable considering the limitations of these bulk lipid-mixing assays and the mild conditions of our experiments. These observations strongly support the notion that synaptotagmin-1 plays a direct role in enabling fast $\mathrm{Ca}^{2+}$ triggered membrane fusion during release. During the publication of this work, another study showed that preincubation with the $\mathrm{C}_{2} \mathrm{AB}$ fragment allows a strong $\mathrm{Ca}^{2+}$-dependent stimulation of SNARE-dependent lipid mixing, which is further enhanced by a synaptobrevin C-terminal peptide38; while the maximum lipid-mixing rates reported ( $\tau \sim 43$ $s$ at $1 \mathrm{mM} \mathrm{Ca}^{2+}$ and $20 \mu \mathrm{M} \mathrm{C}_{2} \mathrm{AB}$ fragment) were not as fast as those described here, these data likely reflect the same fundamental property of synaptotagmin-1 that underlies our results and also support its proposed role in $\mathrm{Ca}^{2+}$-triggered fusion.

As observed in earlier reconstitutions 35,37 , our experiments with $\mathrm{C}_{2} \mathrm{AB}$ fragment do not reproduce the relative importance of the $\mathrm{C}_{2}$ domain $\mathrm{Ca}^{2+}$-binding sites observed in vivo (Fig. 5e,6). This discrepancy may arise because the $\mathrm{C}_{2} \mathrm{AB}$ fragment may support lipidmixing stimulation by binding to two apposed membranes with diverse relative orientations of the two $\mathrm{C}_{2}$ domains, some of which may be irrelevant in vivo (note that single $\mathrm{Ca}^{2+}$ binding site mutations do prevent vesicle clustering by the $\mathrm{C}_{2} \mathrm{AB}$ fragment; Fig. $4 \mathrm{~b}$ ). Despite this caveat, it seems highly unlikely that the lipid-mixing stimulation caused by $\mathrm{Ca}^{2+}$ in the presence of $\mathrm{C}_{2} \mathrm{AB}$ fragment arises from completely irrelevant interactions. First, the strong impairment of the $\mathrm{C}_{2} \mathrm{AB}$ fragment activity in the lipid-mixing assays caused by the R398Q,R399Q mutation (Fig. 5c) shows that this activity depends on some specific interactions, and clearly correlates with the disruption of release caused by this mutation (Fig. 2,3). Second, the isolated $\mathrm{C}_{2} \mathrm{~B}$ domain, but not the $\mathrm{C}_{2} \mathrm{~A}$ domain, can support fast $\mathrm{Ca}^{2+}$ induced lipid mixing (Fig. 5f), in agreement with the preponderant role of the $\mathrm{C}_{2} \mathrm{~B}$ domain for release19-23. Third, lipid-mixing stimulation is abrogated by both the R398Q,R399Q mutation and the $\mathrm{D} 309 \mathrm{~N}$ mutation that disrupts $\mathrm{Ca}^{2+}$ binding when the $\mathrm{C}_{2} \mathrm{~B}$ domain is used (Fig. 5g), in correlation with the effects of these mutations in vivo [Fig. 2 and refs. 19, 20)]. These observations suggest that our reconstitutions reproduce at least in part the events that lead to $\mathrm{Ca}^{2+}$-triggered neurotransmitter release in vivo.

It is noteworthy that these results were obtained with soluble synaptotagmin-1 fragments, whereas reconstitutions with full-length synaptotagmin-1 have been more difficult due to undesired 'cis' interactions with the v-SNARE membrane35 and a tendency to aggregate 38. It is plausible that the proper behavior of full-length synaptotagmin-1 may require additional factors present in vivo, while the essence of the function of its $\mathrm{C}_{2}$ domains can be captured more easily in these in vitro assays with the soluble $\mathrm{C}_{2} \mathrm{AB}$ fragment, likely because their function is mostly associated to interactions with $\mathrm{Ca}^{2+}$, phospholipids and the SNAREs. Note in this context that some synaptotagmin isoforms are localized to vesicles and other to the plasma membrane1, and that the synaptotagmin $\mathrm{C}_{2}$ domains are connected to their TM regions by long linkers, which may allow similar mechanisms of action for the $\mathrm{C}_{2}$ domains regardless of the membrane localization.

The finding that the $\mathrm{Ca}^{2+}$-independent bottom face of the $\mathrm{C}_{2} \mathrm{~B}$ domain is so critical for the $\mathrm{Ca}^{2+}$-dependent function of synaptotagmin-1 may seem paradoxical, but can be easily 
explained by the overall cooperativity of the system. For instance, the bottom face of one $\mathrm{C}_{2} \mathrm{~B}$ domain molecule is insufficient for lipid binding in the absence of $\mathrm{Ca}^{2+}$, but its key role in $\mathrm{Ca}^{2+}$-induced vesicle clustering can be explained because accumulation of multiple $\mathrm{C}_{2} \mathrm{~B}$ domains on one membrane upon $\mathrm{Ca}^{2+}$-dependent binding through its top loops allows cooperation of their bottom faces in binding to a second, closely apposed membrane27. Similar mechanisms, enhanced by specific interactions with SNARE complexes16, 17, 39, likely underlie the key role of the $\mathrm{C}_{2} \mathrm{~B}$ domain bottom face for lipid mixing in vitro and neurotransmitter release in vivo. The fact that synaptotagmin-1 can bring two membranes together, like the SNAREs do but in a $\mathrm{Ca}^{2+}$-dependent manner, and that the top and bottom surfaces of the $\mathrm{C}_{2} \mathrm{~B}$ domain involved in this activity are both critical for neurotransmitter release, strongly support the notion that binding of these surfaces to the apposed vesicle and plasma membranes is fundamental for the action of synaptotagmin-1 in membrane fusion and $\mathrm{Ca}^{2+}$-triggering of release (Fig. 7). These observations suggest an attractive mechanism for the exquisite $\mathrm{Ca}^{2+}$-dependence of release whereby assembly of the $\mathrm{C}$-terminus of the neuronal SNARE complex may not provide sufficient energy to bring the two membrane close enough to induce fusion 40 , and whereby fusion requires cooperation with the $\mathrm{Ca}^{2+}$ dependent activity of synaptotagmin- 1 in binding to the two membranes (note that the $\mathrm{Ca}^{2+}$ sensitivity of release may also involve inhibition by synaptotagmin-1 and complexins before $\mathrm{Ca}^{2+}$ influx27, 30, 38, 41-44). Moreover, the highly positive electrostatic potential provided by the $\mathrm{C}_{2} \mathrm{~B}$ domain and the SNARE complex C-terminus may help to induce negative curvature on the membranes to accelerate fusion17, 27, a notion supported by theoretical calculations 45 .

Conversely, a recent study concluded that synaptotagmin- 1 causes fusion by inducing positive membrane curvature through the $\mathrm{Ca}^{2+}$ binding loops of both $\mathrm{C}_{2}$ domains18. However, the experimental basis for this model arises from liposome tubulation assays performed in high concentrations of uranyl acetate, an agent that strongly perturbs membranes 46,47 , and the $\mathrm{C}_{2} \mathrm{AB}$ fragment induces very little tubulation in the absence of this agent27. Moreover, this model does not provide an explanation for the preponderant role of the $\mathrm{C}_{2} \mathrm{~B}$ domain and predicts that the $\mathrm{C}_{2}$ domain $\mathrm{Ca}^{2+}$ binding loops are oriented towards the fusion pore while the bottom face of the $\mathrm{C}_{2} \mathrm{~B}$ domain is facing away from the site of fusion (Supplementary Fig. 7a online), which makes it difficult to envisage how the R398Q,R399Q mutation can lead to strong impairment of neurotransmitter release and membrane fusion. Note however that that this model is not completely incompatible with the model of Fig. 7, since bending of the membranes to initiate membrane fusion requires both negative and positive curvature (Supplementary Fig. $7 \mathrm{~b}$ online).

Regardless of the validity of these models, our data together with previous studies 19, 20 conclusively demonstrate that synaptotagmin- 1 function depends critically on both the $\mathrm{Ca}^{2+}$ binding top loops and the $\mathrm{Ca}^{2+}$-independent bottom face of the $\mathrm{C}_{2} \mathrm{~B}$ domain, and suggest that this Janus-faced nature is crucial for triggering membrane fusion at the high speeds required for synchronous neurotransmitter release. It is noteworthy that distinct functions have also been proposed for the top and bottom faces of the rabphilin $\mathrm{C}_{2} \mathrm{~B}$ domain 48,49 , suggesting that the ability to interact with apposed targets may be a general property of a subset of $\mathrm{C}_{2}$ domains. 


\section{METHODS}

\section{Animals and cell culture}

Synaptotagmin-1 heterozygous mice were obtained from Dr. Thomas Südhof (University of Texas Southwestern Medical Center, USA)28. Synaptotagmin-1 KO mice were generated by interbreeding the heterozygous mice. All procedures for maintenance and use of these mice were approved by the Institutional Animal Care and Use Committee for Baylor College of Medicine and Affiliates. Astrocytes and hippocampal neurons from postnatal day 0 (P0) mice were cultured as described50. Neurons were plated at a density of $300 \mathrm{~cm}^{-2}$ on microisland astrocyte feeder layers for autaptic electrophysiology and immunocytochemistry. For western blot analyses of protein expression, neurons were plated at a density of $10,000 \mathrm{~cm}^{-2}$ on confluent astrocyte feeder layers.

\section{Lentivirus constructs and production}

A lentiviral vector51 was modified and used, in which a human synapsin-1 promoter and a ubiquitin $\mathrm{C}$ promoter drive the expression of mouse synaptotagmin-1 and enhanced green fluorescent protein (EGFP), respectively. Standard recombinant DNA techniques were used to generate all synaptotagmin-1 mutations. Lentiviruses were produced as described51 and infected neurons within 24 hours after plating neurons.

\section{Western blotting and immunocytochemistry}

Proteins were extracted from cultured neurons and astrocytes as described50. Expression levels of WT and mutant synaptotagmin-1 variants were examined by standard SDS-PAGE and Western blotting. The presynaptic targeting of WT and mutant synaptotagmin-1 variants were examined by immunocytochemistry and confocal microscopy. Neurons were imaged with an 63x oil objective on a Zeiss 510 laser scanning confocal microscope. Images were acquired as z-stacks and processed using NIH ImageJ to create sum projections from the stacks. The primary antibodies (all from Synaptic Systems) were mouse anti- $\beta$-Tubulin III (clone 3B11, 1:4000 for Western blotting), mouse anti-synaptotagmin-1 (clone 41.1, 1:10,000 for Western blotting and 1: 100 for immunocytochemistry) and rabbit antisynaptophysin-1 (1:1000 for immunocytochemistry).

\section{Electrophysiology of autaptic hippocampal neurons}

Whole-cell voltage-clamp recordings were performed on approximately equal numbers of neurons from every group in parallel on the same day in vitro (day 8-12 in vitro) as described50 with modifications. Briefly, the patch pipette solution contained (in $\mathrm{mM}$ ) 136 $\mathrm{KCl}, 17.8$ HEPES, 1 EGTA, $0.6 \mathrm{MgCl}_{2}$, 4 ATP-Mg, $0.3 \mathrm{GTP}-\mathrm{Na}, 12$ phosphocreatine and $50 \mathrm{U} \mathrm{ml}^{-1}$ phosphocreatine kinase ( $300 \mathrm{mOsm}, \mathrm{pH}$ 7.4). The standard external solution contained (in mM) $140 \mathrm{NaCl}, 2.4 \mathrm{KCl}, 10$ HEPES, 10 glucose, $2 \mathrm{CaCl}_{2}, 4 \mathrm{MgCl}_{2}(300$ mOsm, pH 7.4). For the apparent $\mathrm{Ca}^{2+}$-sensitivity of release experiments, the external solution contained $1 \mathrm{mM} \mathrm{Mg}^{2+}$ and various $\mathrm{Ca}^{2+}$ concentrations as indicated. Each test measurement was preceded and followed by a measurement in standard external solution to control for the rundown of synaptic responses. The amplitudes of EPSCs at each $\mathrm{Ca}^{2+}$ concentration were normalized to the amplitudes in standard external solution. All data were 
then normalized to the maximal value (the response in $12 \mathrm{mM} \mathrm{Ca}^{2+}$ ). Data were fitted with a standard Hill equation: $\left.Y=M /\left(1+K_{d} / X\right)^{n}\right) ; Y$, response amplitudes; $X, \mathrm{Ca}^{2+}$ concentrations; $M$, maximum response amplitude; $K_{d}$, dissociation constant; $n$, Hill coefficient. All experiments were performed at room temperature $\left(23-24^{\circ} \mathrm{C}\right)$. Data were analyzed offline using AxoGraph X 1.0 (AxoGraph Scientific) and KaleidaGraph (Synergy Software). Statistical significance was tested using Student's t-test, one-way analysis of variance, or two-way analysis of variance.

\section{Protein expression and purification}

Full-length or a fragment spanning residues 49-96 of rat synaptobrevin-2, full-length human SNAP-25A (with its four cysteines mutated to serines), a rat syntaxin-1A fragment spanning its SNARE motif and transmembrane region (residues 183-288), a rat complexin-1 V61C mutant fragment (residues 26-83), and WT or mutant rat synaptotagmin-1 fragments $\left(\mathrm{C}_{2} \mathrm{~A}\right.$ domain, residues 140-267; $\mathrm{C}_{2} \mathrm{~B}$ domain, residues 271-421; $\mathrm{C}_{2} \mathrm{AB}$ fragment, residues 140-421) were expressed in E. coli and purified as described6, 8, 27, 30, 33, 36, 52, except for a sample of the $\mathrm{WT}_{2} \mathrm{~B}$ domain that was purified by gel filtration on a Superdex 75 column (GE Health Sciences) in PBS (experiment labeled $\mathrm{C}_{2} \mathrm{~B} *$ in Fig. 5f) instead of our standard procedure36. The D178N, D309N and R398Q,R399Q mutants of the $\mathrm{C}_{2} \mathrm{~B}$ domain and $\mathrm{C}_{2} \mathrm{AB}$ fragment were described previously 27 , and expression vectors for the single R398Q and R399Q mutants, as well as the D178N,D309N double mutant, were made using standard recombinant DNA techniques.

\section{Lipid mixing assays}

Proteoliposomes containing either synaptobrevin-2 (v-SNARE) or SNAP-25A (with its four cysteines mutated to serines) and syntaxin-1A(183-288) (t-SNARE) were reconstituted as described33 except that the $\mathrm{P} / \mathrm{L}$ ratio was 1:500 unless otherwise indicated. $v$-SNARE liposomes contained a 5:2:1:1:1 mixture of phosphatidylcholine, phosphatidylethanolamine (PE), phosphatidylserine, phosphatidylinositol, and cholesterol. t-SNARE liposomes contained the same lipid mixture but replacing 20\% PE with 17\% PE, 1.5\% N-NBD-1,2dipalmitoyl PE and 1.5\% N-(lissamine rhodamine B sulfonyl)-1,2-dipalmitoyl PE) (all lipid ratios expressed in mols). Briefly, dried lipid mixtures were resuspended in $20 \mathrm{mM}$ HEPES $\mathrm{pH} 7.4,100 \mathrm{mM} \mathrm{KCl}, 5 \mathrm{mM}$ DTT, $5 \%$ (wt/vol) sodium cholate (13.5 mM total lipid). SNARE proteins solubilized in $20 \mathrm{mM}$ sodium cholate were added in the desired ratio and the mixture was passed through a Fast Desalting PC 3.2/10 column (GE Healthcare) in 20 $\mathrm{mM}$ HEPES $\mathrm{pH} 7.4,150 \mathrm{mM} \mathrm{KCl}, 1 \mathrm{mM}$ DTT. Lipid and protein recoveries in the resulting proteoliposomes were practically quantitative, as the central $1 \mathrm{~mL}$ fraction collected from the size-exclusion column contained 75\%-95\% of the starting materials based on the lipid absorption at $574 \mathrm{~nm}$ and comparison with standard protein samples of know concentration using Coomassie Blue-stained SDS-PAGE gels (see Supplementary Fig. 8 online for a gel of representative proteoliposomes). For lipid mixing assays, v-SNARE and t-SNARE liposomes [the latter mixed with an equimolar amount of synaptobrevin(49-96)] were separately incubated for $1 \mathrm{hr}$ at $37^{\circ} \mathrm{C}$ and then mixed at $37^{\circ} \mathrm{C}$ in $20 \mathrm{mM} \mathrm{HEPES} \mathrm{pH} \mathrm{7.4,}$ $150 \mathrm{mM} \mathrm{KCl}, 1 \mathrm{mM}$ DTT (0.4 mL final volume; $500 \mathrm{nM}$ final protein concentration). NBD fluorescence emission at $538 \mathrm{~nm}$ (excitation $460 \mathrm{~nm}$ ) was monitored with a PTI 
spectrofluorimeter. Synaptotagmin-1 fragments ( $1 \mu \mathrm{M}$ final concentration) were added at the beginning of the reaction and divalent cations were added after $250 \mathrm{~s}$.

\section{Miscellaneous procedures}

Complexin displacement assays were performed in $25 \mathrm{mM}$ HEPES pH7.4, $100 \mathrm{mM} \mathrm{KCl}, 0.1$ mM EGTA, 0.3mM TCEP, $1 \mathrm{mM} \mathrm{Ca}^{2+}$ as described17, 30. Briefly, supported bilayers containing assembled SNARE complexes deposited within single microfluidic channels were incubated with $50 \mathrm{nM}$ BODIPY-FL labeled V61C-complexin 1(26-83) for $15 \mathrm{~min}$, and unbound complexin was washed out. Unlabeled WT or R398Q,R399Q mutant $\mathrm{C}_{2} \mathrm{AB}$ fragment at the desired concentration was added and incubated for $10 \mathrm{~min}$, followed by a wash with buffer. BODIPY-FL fluorescence was measured with a Leica (Wetzlar, Germany) confocal microscope (TCS SP2) and quantified with Image J (NIH, MD). Average fluorescence intensities measured under each condition were normalized to a control where the complexin-1 fragment was added to plain supported bilayers17.

Vesicle clustering assays were performed basically as described 27 but with modifications. Briefly, $100 \mathrm{~nm}$ liposomes prepared by extrusion (DOPS/POPC 30:70) were mixed with the corresponding synaptotagmin-1 fragment in $40 \mathrm{mM}$ Hepes (pH 7.5), $100 \mathrm{mM} \mathrm{NaCl}(0.05$ $\mathrm{mg} \mathrm{ml}^{-1}$ lipids; $0.5 \mu \mathrm{M}$ protein), and particle size as a function of time after addition of 100 $\mu \mathrm{M} \mathrm{Ca}^{2+}$ was measured by DLS using a Protein Solutions DynaPro instrument.

\section{Supplementary Material}

Refer to Web version on PubMed Central for supplementary material.

\section{Acknowledgments}

We thank Hui Deng and Hongmei Chen for technical assistance, Richard Atkinson for assistance in confocal microscopy, Carlos Lois (Massachusetts Institute of Technology) and Ralf Nehring (Bayolor College of Medicine) for providing the lentiviral vectors, Thomas Südhof (Stanford University) for providing synaptotagmin-1 heterozygous mice, and Raquel Castillejos (Harvard University) for providing silicon masters for molding microchannels. This work was supported by the Baylor College of Medicine Mental Retardation and Developmental Disabilities Research Center, and by NIH grants NS50655 (to C.R.), NS40944 (to J.R.) and GM65364 (to George M. Whitesides, Harvard University).

\section{References}

1. Sudhof TC. The synaptic vesicle cycle. Annu Rev Neurosci. 2004; 27:509-547. [PubMed: 15217342]

2. Rizo J, Chen X, Arac D. Unraveling the mechanisms of synaptotagmin and SNARE function in neurotransmitter release. Trends Cell Biol. 2006; 16:339-350. [PubMed: 16698267]

3. Chapman ER. How Does Synaptotagmin Trigger Neurotransmitter Release? Annu Rev Biochem. 2008

4. Sutton RB, Davletov BA, Berghuis AM, Sudhof TC, Sprang SR. Structure of the first C2 domain of synaptotagmin I: a novel Ca2+/phospholipid-binding fold. Cell. 1995; 80:929-938. [PubMed: 7697723]

5. Shao X, Davletov BA, Sutton RB, Sudhof TC, Rizo J. Bipartite Ca2+-binding motif in C2 domains of synaptotagmin and protein kinase C. Science. 1996; 273:248-251. [PubMed: 8662510]

6. Ubach J, Zhang X, Shao X, Sudhof TC, Rizo J. Ca2+ binding to synaptotagmin: how many Ca2+ ions bind to the tip of a C2-domain? EMBO J. 1998; 17:3921-3930. [PubMed: 9670009] 
7. Shao X, Fernandez I, Sudhof TC, Rizo J. Solution structures of the Ca2+-free and Ca2+-bound C2A domain of synaptotagmin I: does Ca2+ induce a conformational change? Biochemistry. 1998; 37:16106-16115. [PubMed: 9819203]

8. Fernandez I, et al. Three-dimensional structure of the synaptotagmin $1 \mathrm{c}(2) \mathrm{b}$-domain. Synaptotagmin 1 as a phospholipid binding machine. Neuron. 2001; 32:1057-1069. [PubMed: 11754837]

9. Chapman ER, Davis AF. Direct interaction of a Ca2+-binding loop of synaptotagmin with lipid bilayers. J Biol Chem. 1998; 273:13995-14001. [PubMed: 9593749]

10. Zhang X, Rizo J, Sudhof TC. Mechanism of phospholipid binding by the C2A-domain of synaptotagmin I. Biochemistry. 1998; 37:12395-12403. [PubMed: 9730811]

11. Herrick DZ, Sterbling S, Rasch KA, Hinderliter A, Cafiso DS. Position of synaptotagmin I at the membrane interface: cooperative interactions of tandem C2 domains. Biochemistry. 2006; 45:9668-9674. [PubMed: 16893168]

12. Fernandez-Chacon R, et al. Synaptotagmin I functions as a calcium regulator of release probability. Nature. 2001; 410:41-49. [PubMed: 11242035]

13. Rhee JS, et al. Augmenting neurotransmitter release by enhancing the apparent $\mathrm{Ca} 2+$ affinity of synaptotagmin 1. Proc Natl Acad Sci U S A. 2005; 102:18664-18669. [PubMed: 16352718]

14. Brunger AT. Structure and function of SNARE and SNARE-interacting proteins. Q Rev Biophys. 2005:1-47. [PubMed: 16336742]

15. Jahn R, Scheller RH. SNAREs--engines for membrane fusion. Nat Rev Mol Cell Biol. 2006; 7:631-643. [PubMed: 16912714]

16. Bhalla A, Chicka MC, Tucker WC, Chapman ER. Ca(2+)-synaptotagmin directly regulates tSNARE function during reconstituted membrane fusion. Nat Struct Mol Biol. 2006; 13:323-330. [PubMed: 16565726]

17. Dai H, Shen N, Arac D, Rizo J. A Quaternary SNARE-Synaptotagmin-Ca(2+)-Phospholipid Complex in Neurotransmitter Release. J Mol Biol. 2007; 367:848-863. [PubMed: 17320903]

18. Martens S, Kozlov MM, McMahon HT. How synaptotagmin promotes membrane fusion. Science. 2007; 316:1205-1208. [PubMed: 17478680]

19. Mackler JM, Drummond JA, Loewen CA, Robinson IM, Reist NE. The C(2)B Ca(2+)-binding motif of synaptotagmin is required for synaptic transmission in vivo. Nature. 2002; 418:340-344. [PubMed: 12110842]

20. Nishiki T, Augustine GJ. Dual roles of the C2B domain of synaptotagmin I in synchronizing Ca2+dependent neurotransmitter release. J Neurosci. 2004; 24:8542-8550. [PubMed: 15456828]

21. Robinson IM, Ranjan R, Schwarz TL. Synaptotagmins I and IV promote transmitter release independently of $\mathrm{Ca}(2+)$ binding in the $\mathrm{C}(2)$ A domain. Nature. 2002; 418:336-340. [PubMed: 12110845]

22. Fernandez-Chacon R. Structure/function analysis of $\mathrm{Ca} 2+$ binding to the $\mathrm{C} 2 \mathrm{~A}$ domain of synaptotagmin 1. J Neurosci. 2002; 22:8438-8446. [PubMed: 12351718]

23. Stevens CF, Sullivan JM. The synaptotagmin C2A domain is part of the calcium sensor controlling fast synaptic transmission. Neuron. 2003; 39:299-308. [PubMed: 12873386]

24. Rickman C, et al. Conserved prefusion protein assembly in regulated exocytosis. Mol Biol Cell. 2006; 17:283-294. [PubMed: 16267273]

25. Li L, et al. Phosphatidylinositol phosphates as co-activators of $\mathrm{Ca} 2+$ binding to $\mathrm{C} 2$ domains of synaptotagmin 1. J Biol Chem. 2006; 281:15845-15852. [PubMed: 16595652]

26. Mackler JM, Reist NE. Mutations in the second C2 domain of synaptotagmin disrupt synaptic transmission at Drosophila neuromuscular junctions. J Comp Neurol. 2001; 436:4-16. [PubMed: 11413542]

27. Arac D, et al. Close membrane-membrane proximity induced by $\mathrm{Ca}(2+)$-dependent multivalent binding of synaptotagmin-1 to phospholipids. Nat Struct Mol Biol. 2006; 13:209-217. [PubMed: 16491093]

28. Geppert M, et al. Synaptotagmin I: a major $\mathrm{Ca} 2+$ sensor for transmitter release at a central synapse. Cell. 1994; 79:717-727. [PubMed: 7954835] 
29. Rosenmund C, Stevens CF. Definition of the readily releasable pool of vesicles at hippocampal synapses. Neuron. 1996; 16:1197-1207. [PubMed: 8663996]

30. Tang J, et al. A complexin/synaptotagmin 1 switch controls fast synaptic vesicle exocytosis. Cell. 2006; 126:1175-1187. [PubMed: 16990140]

31. Weber T, et al. SNAREpins: minimal machinery for membrane fusion. Cell. 1998; 92:759-772. [PubMed: 9529252]

32. Tucker WC, Weber T, Chapman ER. Reconstitution of Ca2+-regulated membrane fusion by synaptotagmin and SNAREs. Science. 2004; 304:435-438. [PubMed: 15044754]

33. Pobbati AV, Stein A, Fasshauer D. N- to C-terminal SNARE complex assembly promotes rapid membrane fusion. Science. 2006; 313:673-676. [PubMed: 16888141]

34. Parlati F, et al. Rapid and efficient fusion of phospholipid vesicles by the alpha-helical core of a SNARE complex in the absence of an N-terminal regulatory domain. Proc Natl Acad Sci U S A. 1999; 96:12565-12570. [PubMed: 10535962]

35. Stein A, Radhakrishnan A, Riedel D, Fasshauer D, Jahn R. Synaptotagmin activates membrane fusion through a $\mathrm{Ca}(2+)$-dependent trans interaction with phospholipids. Nat Struct Mol Biol. 2007; 14:904-911. [PubMed: 17891149]

36. Ubach J, et al. The $\mathrm{C} 2 \mathrm{~B}$ domain of synaptotagmin I is a Ca2+-binding module. Biochemistry. 2001; 40:5854-5860. [PubMed: 11352720]

37. Bhalla A, Tucker WC, Chapman ER. Synaptotagmin isoforms couple distinct ranges of Ca2+, $\mathrm{Ba} 2+$, and $\mathrm{Sr} 2+$ concentration to SNARE-mediated membrane fusion. Mol Biol Cell. 2005; 16:4755-4764. [PubMed: 16093350]

38. Chicka MC, Hui E, Liu H, Chapman ER. Synaptotagmin arrests the SNARE complex before triggering fast, efficient membrane fusion in response to Ca2+ Nat Struct Mol Biol. 2008; 15:827835. [PubMed: 18622390]

39. Bowen ME, Weninger K, Ernst J, Chu S, Brunger AT. Single-molecule studies of synaptotagmin and complexin binding to the SNARE complex. Biophys J. 2005; 89:690-702. [PubMed: 15821166]

40. Rizo J, Rosenmund C. Synaptic vesicle fusion. Nat Struct Mol Biol. 2008; 15:665-674. [PubMed: 18618940]

41. Shao X, et al. Synaptotagmin-syntaxin interaction: the $\mathrm{C} 2$ domain as a $\mathrm{Ca} 2+$-dependent electrostatic switch. Neuron. 1997; 18:133-142. [PubMed: 9010211]

42. Giraudo CG, Eng WS, Melia TJ, Rothman JE. A clamping mechanism involved in SNAREdependent exocytosis. Science. 2006; 313:676-680. [PubMed: 16794037]

43. Schaub JR, Lu X, Doneske B, Shin YK, McNew JA. Hemifusion arrest by complexin is relieved by Ca2+-synaptotagmin I. Nat Struct Mol Biol. 2006; 13:748-750. [PubMed: 16845390]

44. Huntwork S, Littleton JT. A complexin fusion clamp regulates spontaneous neurotransmitter release and synaptic growth. Nat Neurosci. 2007; 10:1235-1237. [PubMed: 17873870]

45. Zimmerberg J, Akimov SA, Frolov V. Synaptotagmin: fusogenic role for calcium sensor? Nat Struct Mol Biol. 2006; 13:301-303. [PubMed: 16715046]

46. Parsegian VA, Rand RP, Stamatoff J. Perturbation of membrane structure by uranyl acetate labeling. Biophys J. 1981; 33:475-477. [PubMed: 6164411]

47. Winiski AP, McLaughlin AC, McDaniel RV, Eisenberg M, McLaughlin S. An experimental test of the discreteness-of-charge effect in positive and negative lipid bilayers. Biochemistry. 1986; 25:8206-8214. [PubMed: 3814579]

48. Ubach J, Garcia J, Nittler MP, Sudhof TC, Rizo J. Structure of the Janus-faced C2B domain of rabphilin. Nat Cell Biol. 1999; 1:106-112. [PubMed: 10559882]

49. Deak F, et al. Rabphilin regulates SNARE-dependent re-priming of synaptic vesicles for fusion. EMBO J. 2006; 25:2856-2866. [PubMed: 16763567]

50. Xue M, et al. Distinct domains of complexin I differentially regulate neurotransmitter release. Nat Struct Mol Biol. 2007; 14:949-958. [PubMed: 17828276]

51. Lois C, Hong EJ, Pease S, Brown EJ, Baltimore D. Germline transmission and tissue-specific expression of transgenes delivered by lentiviral vectors. Science. 2002; 295:868-872. [PubMed: 11786607] 
52. Chen X, et al. SNARE-Mediated Lipid Mixing Depends on the Physical State of the Vesicles. Biophys J. 2006; 90:2062-2074. [PubMed: 16361343] 

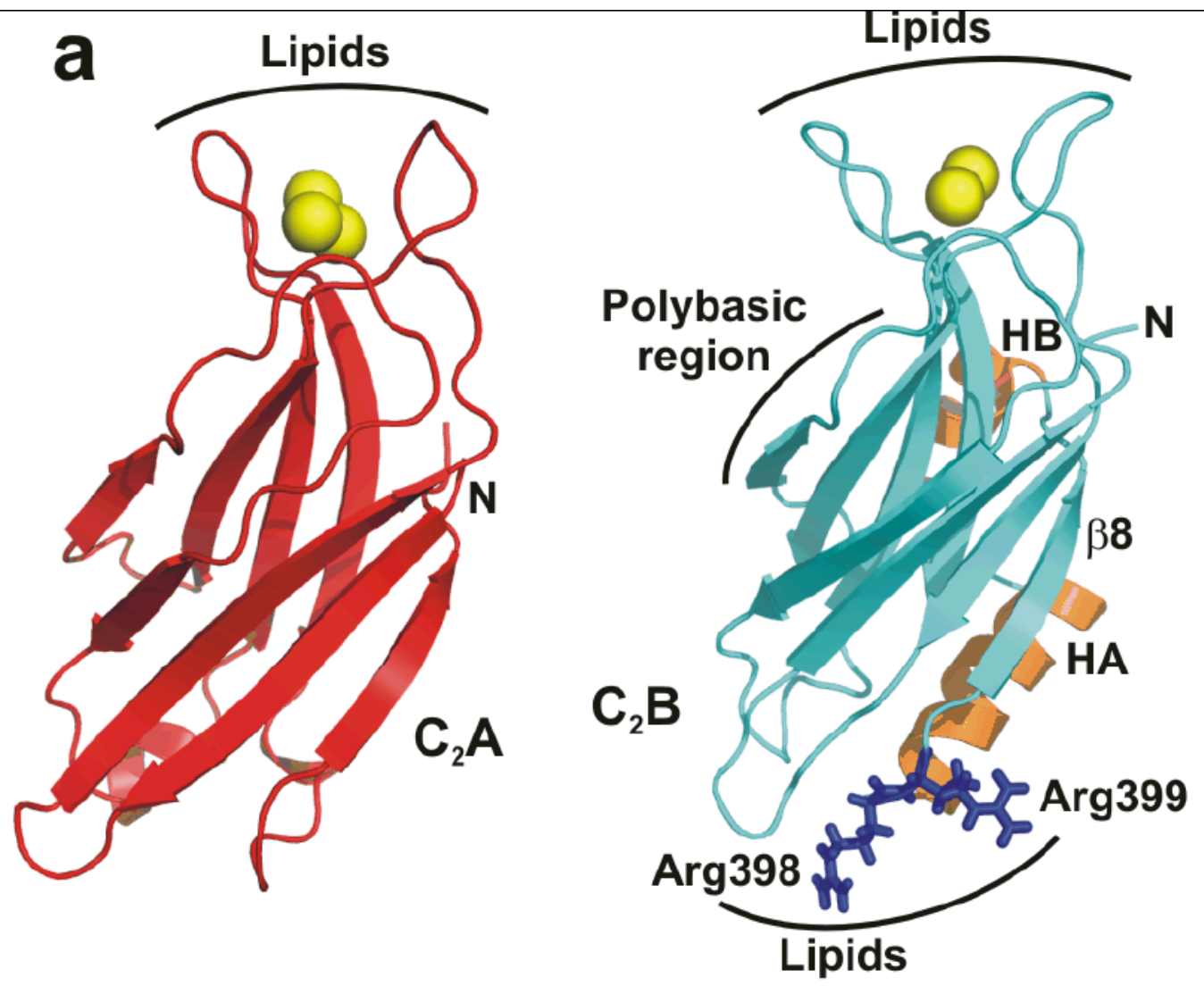

b

HA

** $\beta 8$

HB

Mamm. ELRHWSDMLANPRRPIAQWHTLOV-EEEVDAMLAVKK

Chick ELRHWSDMLANPRRPIAQWHTLQP-FEEVDAMLAVKK

Torp. ELRHWSDMLANPRRPIAQWHTLQP-EEEVDATLGMKK

C.e. ELRHWMDMLASPRRPIAQWHTLGPVEEEGDKKDDKK

D.m. ELRHWSDMLASPRRPIAQWHTLKD-PEETDEILKNMK

Aply. ELRHWSDMLANPRRPIAQWHTLQEFPEKN

Squid GLRHWSDMLANPRRPVAQWHTLQEVPEKN

Figure 1.

Two highly conserved arginines at the bottom face of the synaptotagmin- $1 \mathrm{C}_{2} \mathrm{~B}$ domain. (a) Ribbon diagrams of the synaptotagmin- $1 \mathrm{C}_{2} \mathrm{~A}$ and $\mathrm{C}_{2} \mathrm{~B}$ domain 7, 8 illustrating their structural differences. $\mathrm{Ca}^{2+}$ ions are shown as yellow spheres, helices $\mathrm{HA}$ and $\mathrm{HB}$ of the $\mathrm{C}_{2} \mathrm{~B}$ domain are colored in orange, and R398 and R399 are shown in blue stick models. Strand $\beta 8$ of the $\mathrm{C}_{2} \mathrm{~B}$ domain is labeled. The lipid-binding sites of both $\mathrm{C}_{2}$ domains are indicated. The binding site for the SNARE complex is tentatively assumed to be in the polybasic region on one side of the $\mathrm{C}_{2} \mathrm{~B}$ domain $\beta$-sandwich17, but note that this region has also been implicated in other interactions, including lipid binding25. (b) Sequence alignment 
of the $\mathrm{C}$-terminal region of synaptotagmin-1 $\mathrm{C}_{2} \mathrm{~B}$ domains from different species. Conserved residues are colored in red (helices $\mathrm{HA}$ and $\mathrm{HB}$ ), blue (loops) and yellow (strand $\beta 8$ ). 

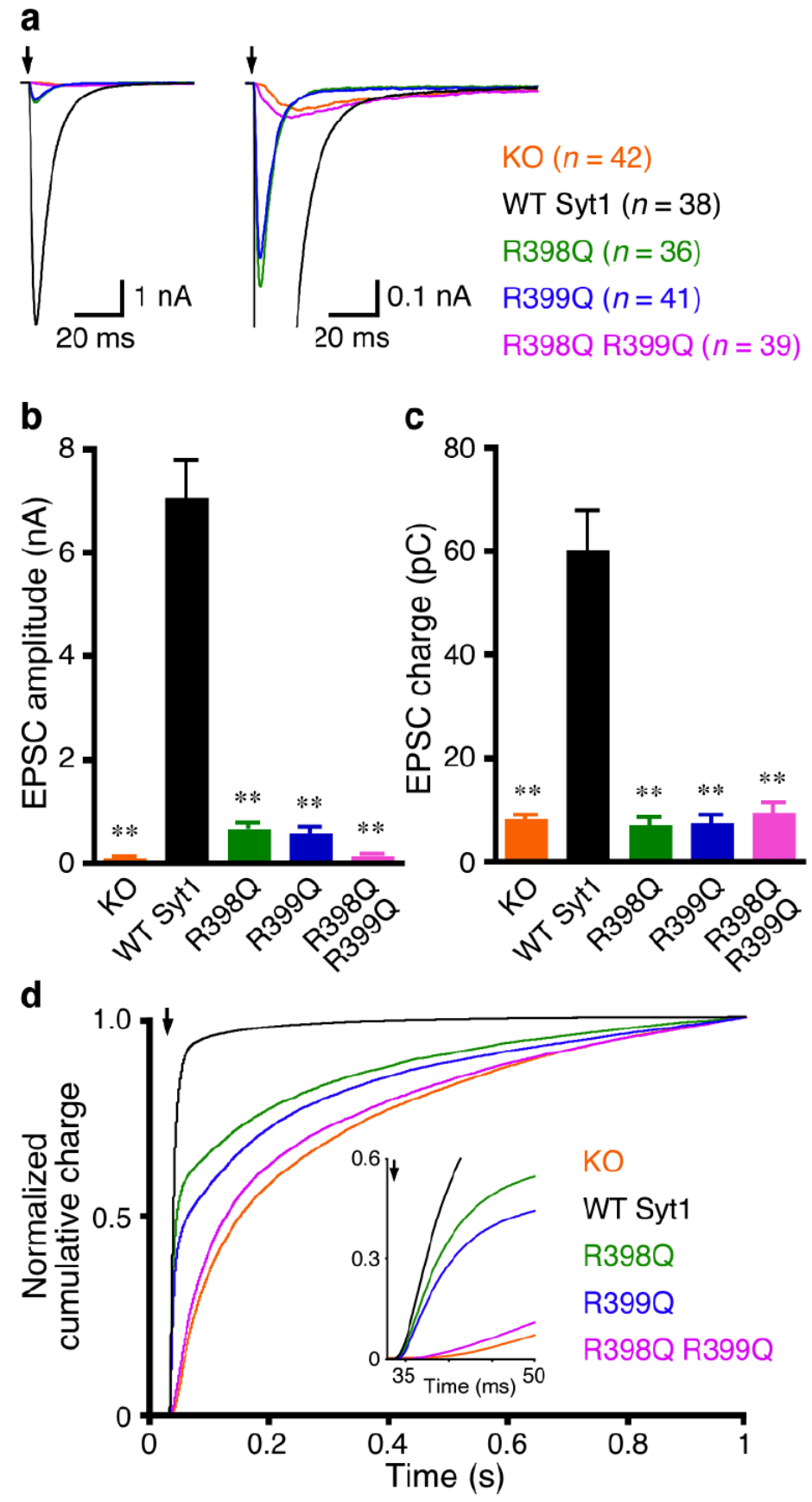

Figure 2.

The bottom face of the synaptotagmin- $1 \mathrm{C}_{2} \mathrm{~B}$ domain is critical for fast $\mathrm{Ca}^{2+}$-triggered neurotransmitter release. (a) Average traces of basal evoked EPSCs of hippocampal synaptotagmin-1 KO neurons and KO neurons rescued with WT and mutant synaptotagmin-1 (Syt1) variants. Arrows represent 2-ms somatic depolarizations to $0 \mathrm{mV}$. Depolarization artifacts and action potentials were blanked. (b,c) Summary data of EPSC amplitude (b) and charge (c). Data are expressed as mean \pm s.e.m. $* * P<0.001$ as compared to KO neurons rescued by WT synaptotagmin-1. (d) Summary plot of the normalized 
cumulative EPSC charge in $1 \mathrm{~s}$. The inset shows the same normalized cumulative EPSC charge within the first $50 \mathrm{~ms}$. Numbers of neurons analyzed in (a-d) are indicated in panel

(a). 


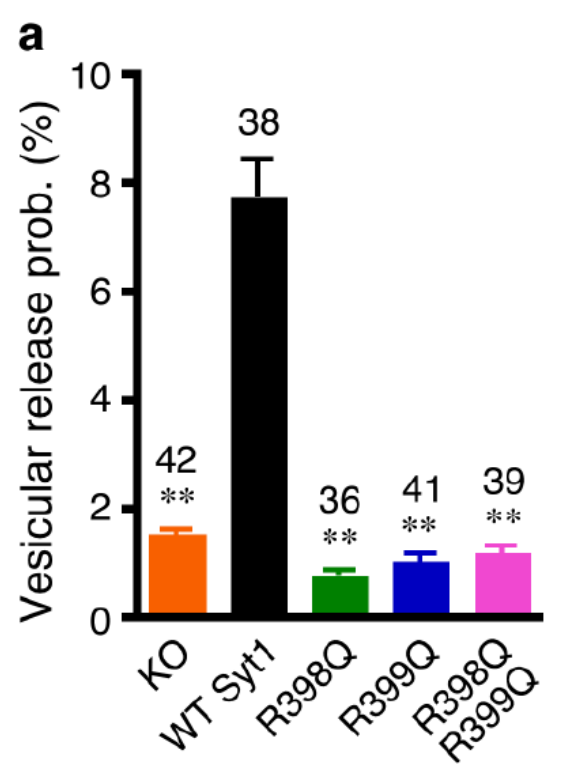

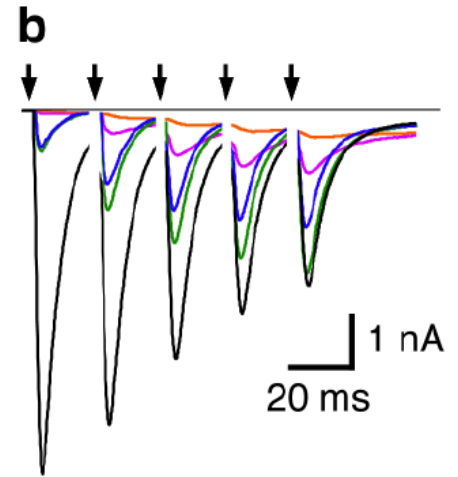

$\mathrm{KO}(n=31)$

WT Syt1 $(n=33)$

$\operatorname{R398Q}(n=31)$

$\operatorname{R399Q}(n=33)$

R398Q R399Q $(n=31)$

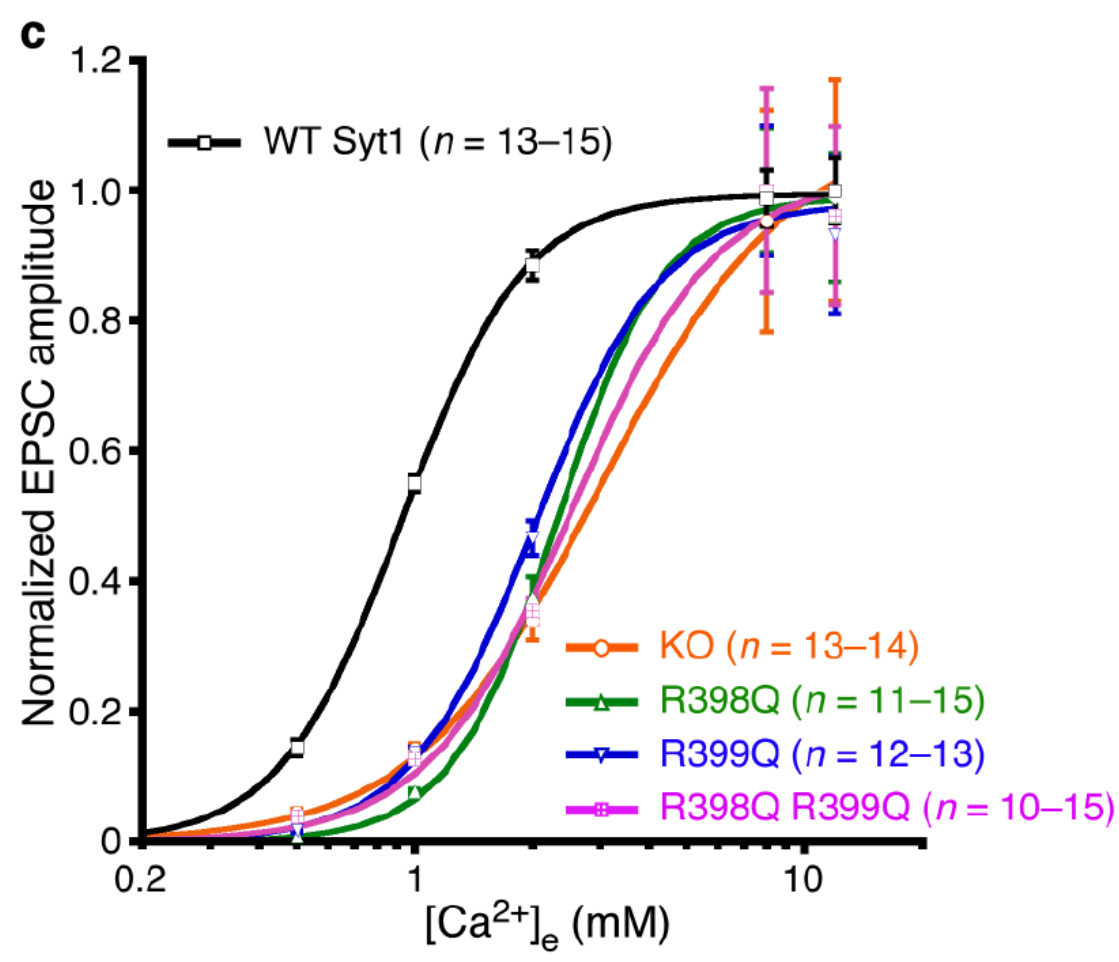

Figure 3.

The bottom face of the synaptotagmin- $1 \mathrm{C}_{2} \mathrm{~B}$ domain regulates probability and $\mathrm{Ca}^{2+}$ sensitivity of release. (a) Summary data of vesicular release probability from synaptotagmin-1 KO neurons and KO neurons rescued with WT and mutant synaptotagmin-1 variants. Data are expressed as mean \pm s.e.m. $* * P<0.001$ as compared to KO neurons rescued by WT synaptotagmin-1. (b) Average traces of 5 consecutive EPSCs evoked at $50 \mathrm{~Hz}$. Arrows represent 2-ms somatic depolarizations to $0 \mathrm{mV}$. Depolarization artifacts and action potentials were blanked. (c) Apparent $\mathrm{Ca}^{2+}$-sensitivity of evoked release. 
Normalized amplitudes of synaptic responses were plotted against external $\mathrm{Ca}^{2+}$ concentrations $\left(\left[\mathrm{Ca}^{2+}\right]_{\mathrm{e}}\right)$. Data are expressed as mean \pm s.e.m. and fitted with standard Hill equation. KO, $K_{d}=3.0 \pm 0.2 \mathrm{mM}$, WT Syt $1, K_{d}=0.93 \pm 0.01 \mathrm{mM}, \mathrm{R} 398 \mathrm{Q}, K_{d}=2.3 \pm 0.1$ $\mathrm{mM}, \mathrm{R} 399 \mathrm{Q}, K_{d}=2.0 \pm 0.1 \mathrm{mM}, \mathrm{R} 398 \mathrm{Q}, \mathrm{R} 399 \mathrm{Q}, K_{d}=2.6 \pm 0.3 \mathrm{mM}$. Numbers of neurons analyzed in (a-c) are indicated in the panels. 
a
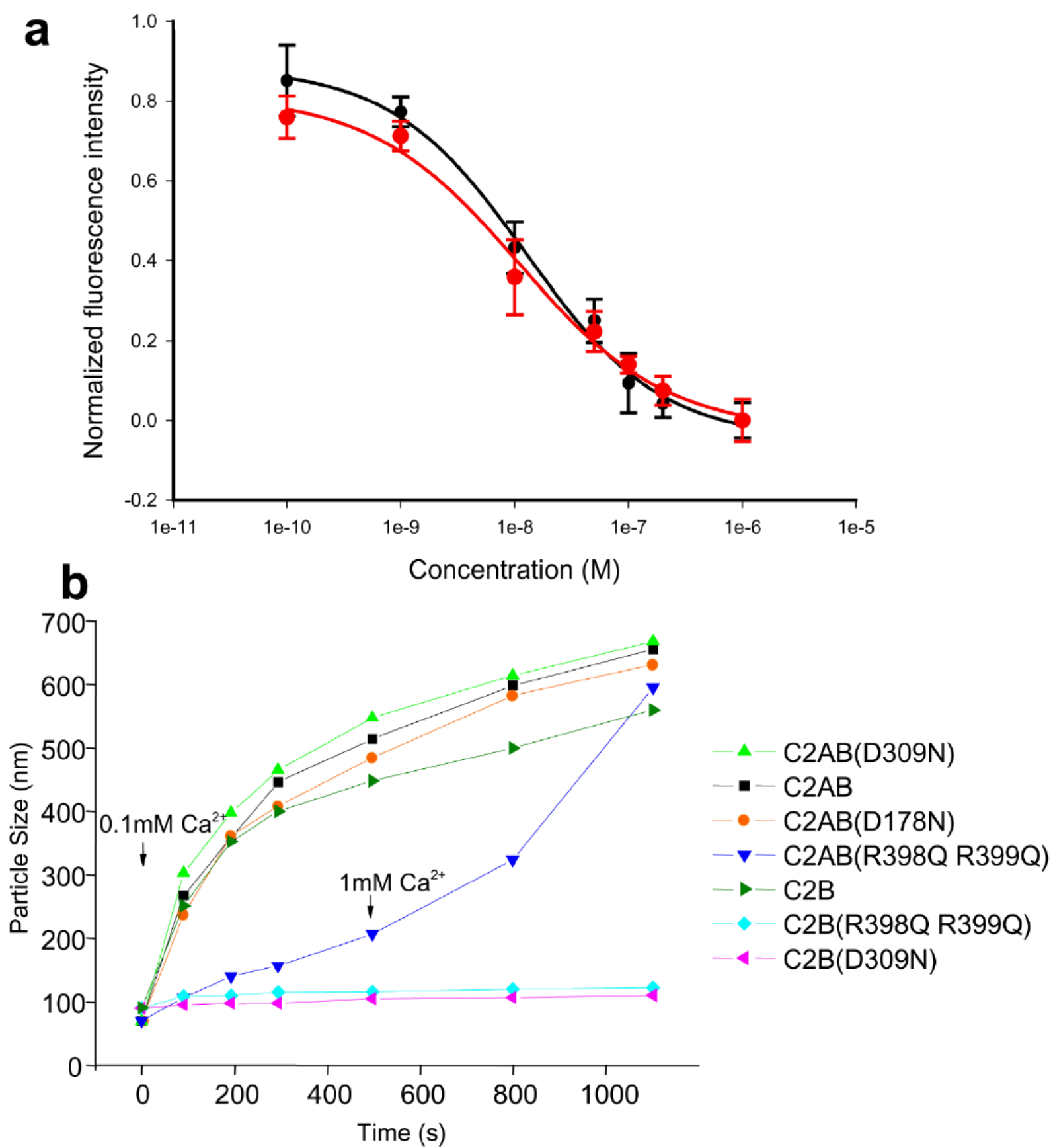

Figure 4.

The R398Q,R399Q mutation impairs synaptotagmin-1/membrane interactions. (a) The R398Q,R399Q mutation does not impair the ability of the $\mathrm{C}_{2} \mathrm{AB}$ fragment to displace a complexin-1 fragment from membrane-anchored SNARE complexes. Supported phospholipid bilayers containing reconstituted SNARE complexes were deposited into microchannels, a rat complexin-1 fragment (residues 26-83) labeled with BODIPY-FL was bound to the SNARE complexes, and displacement of the labeled complexin 1 fragment by increasing concentrations of $\mathrm{C}_{2} \mathrm{AB}$ fragment (black circles) or $\mathrm{C}_{2} \mathrm{AB}-\mathrm{R} 398 \mathrm{Q}, \mathrm{R} 399 \mathrm{Q}$ 
fragment (red circles) was monitored with a confocal fluorescence microscope as described17, 30. The data were normalized to the background fluorescence. Error bars represent SEMs derived from three separate measurements. Fitting of the data to a doseresponse curved yielded an EC50 of $12 \mathrm{nM}$ for both the WT and mutant $\mathrm{C}_{2} \mathrm{AB}$ fragment, which is comparable to earlier results obtained for $\mathrm{WT} \mathrm{C}_{2} \mathrm{AB}$ fragment30. (b) The R398Q,R399Q mutation impairs the vesicle clustering activity of the $\mathrm{C}_{2} \mathrm{AB}$ fragment. Mixtures of liposomes (100 nm average size) with WT or mutant $\mathrm{C}_{2} \mathrm{~B}$ domain or $\mathrm{C}_{2} \mathrm{AB}$ fragment were prepared as described27, and the change in particle size as a function of time was measured by DLS after addition of $100 \mu \mathrm{M} \mathrm{Ca}^{2+}$. For the experiment performed with the R398Q,R399Q mutant $\mathrm{C}_{2} \mathrm{AB}$ fragment, $1 \mathrm{mM} \mathrm{Ca}^{2+}$ was added after $500 \mathrm{~s}$. 

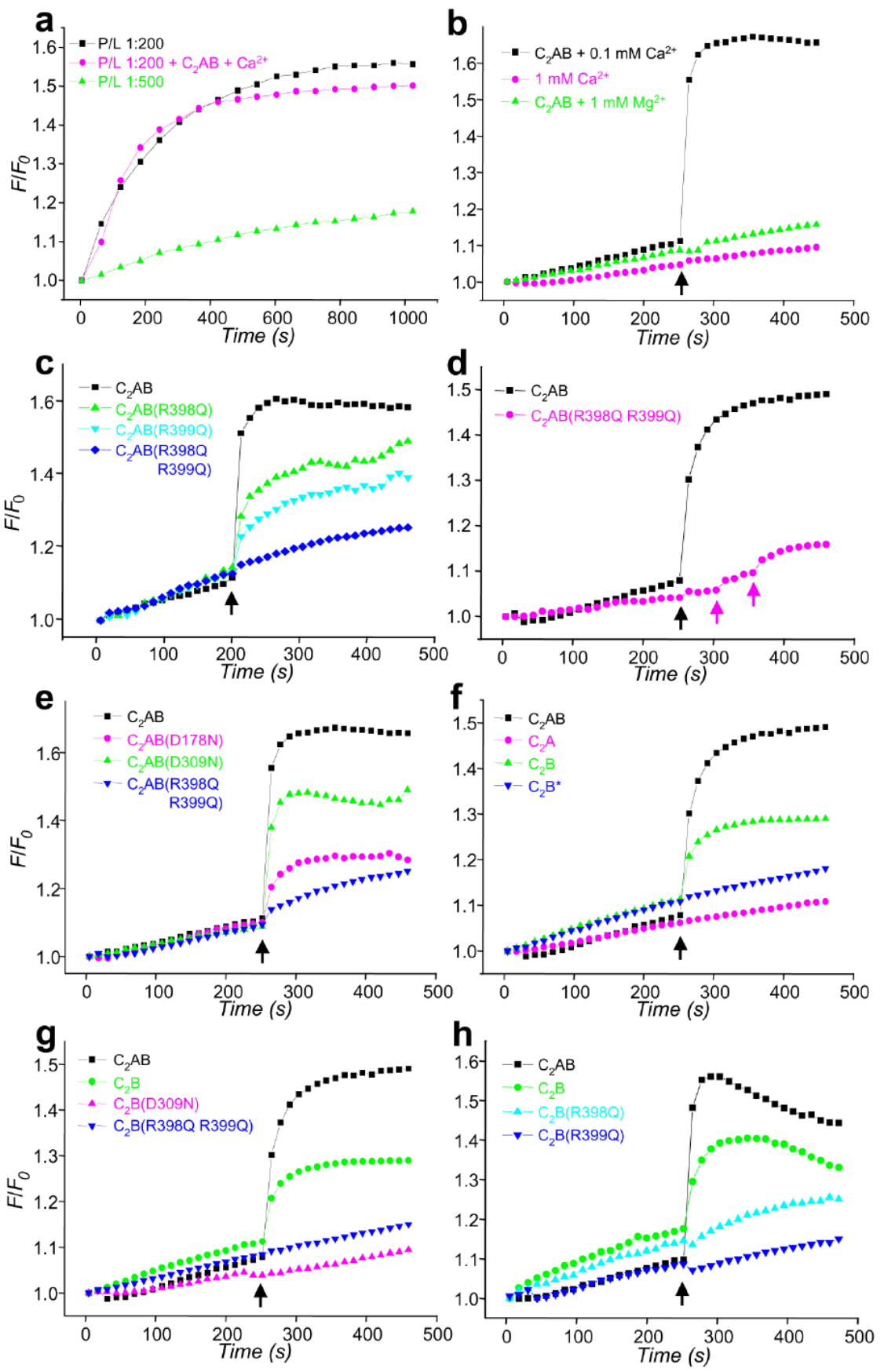

Figure 5.

$\mathrm{Ca}^{2+}$ and synaptotagmin-1 induce a drastic increase in the rate of SNARE-mediated lipid mixing that is abolished by the R398Q,R399Q mutation. (a) Lipid mixing between synaptobrevin- and syntaxin-1/SNAP-25-containing proteoliposomes with 1:200 (black) or 1:500 (green) P/L ratios. Equal amounts of the proteoliposomes were mixed, and lipid mixing was detected by monitoring lipid fluorescence dequenching. In all experiments, the syntaxin-1/SNAP-25 liposomes were preincubated with a C-terminal synaptobrevin fragment (residues 49-96). $\mathrm{F} / \mathrm{F}_{0}$ represents the fluorescence relative to the starting point. The 
pink trace shows an experiment performed with a 1:200 P/L ratio in the presence of $1 \mu \mathrm{M}$ $\mathrm{C}_{2} \mathrm{AB}$ fragment and $100 \mu \mathrm{M} \mathrm{Ca}^{2+}$. (b-h) Lipid-mixing assays were performed as in (a) with a 1:500 P/L ratio plus different additions as indicated. Synaptotagmin-1 fragments $(1 \mu \mathrm{M})$ were added at the beginning of the fusion reaction. In (b), $\mathrm{Ca}^{2+}$ or $\mathrm{Mg}^{2+}$ was added after 250 $\mathrm{s}$ of reaction (black arrows) as indicated. In (c-h), $100 \mu \mathrm{M} \mathrm{Ca}^{2+}$ was added at $250 \mathrm{~s}$ (black arrows). In (d), subsequent additions of $200 \mu \mathrm{M}$ and $1 \mathrm{mM} \mathrm{Ca}^{2+}$ for a reaction with the $\mathrm{C}_{2} \mathrm{AB}-\mathrm{R} 398 \mathrm{Q}, \mathrm{R} 399 \mathrm{Q}$ mutant are indicated by pink arrows. WT and mutant $\mathrm{C}_{2} \mathrm{~B}$ domains were purified using our standard protocol36, except for one experiment where the WT $\mathrm{C}_{2} \mathrm{~B}$ domain was purified under less stringent conditions [indicated as $\mathrm{C}_{2} \mathrm{~B}^{*}$; blue triangles in (f)]. Each set of experiments shown in each panel was performed on the same day with the same proteoliposome preparations. 


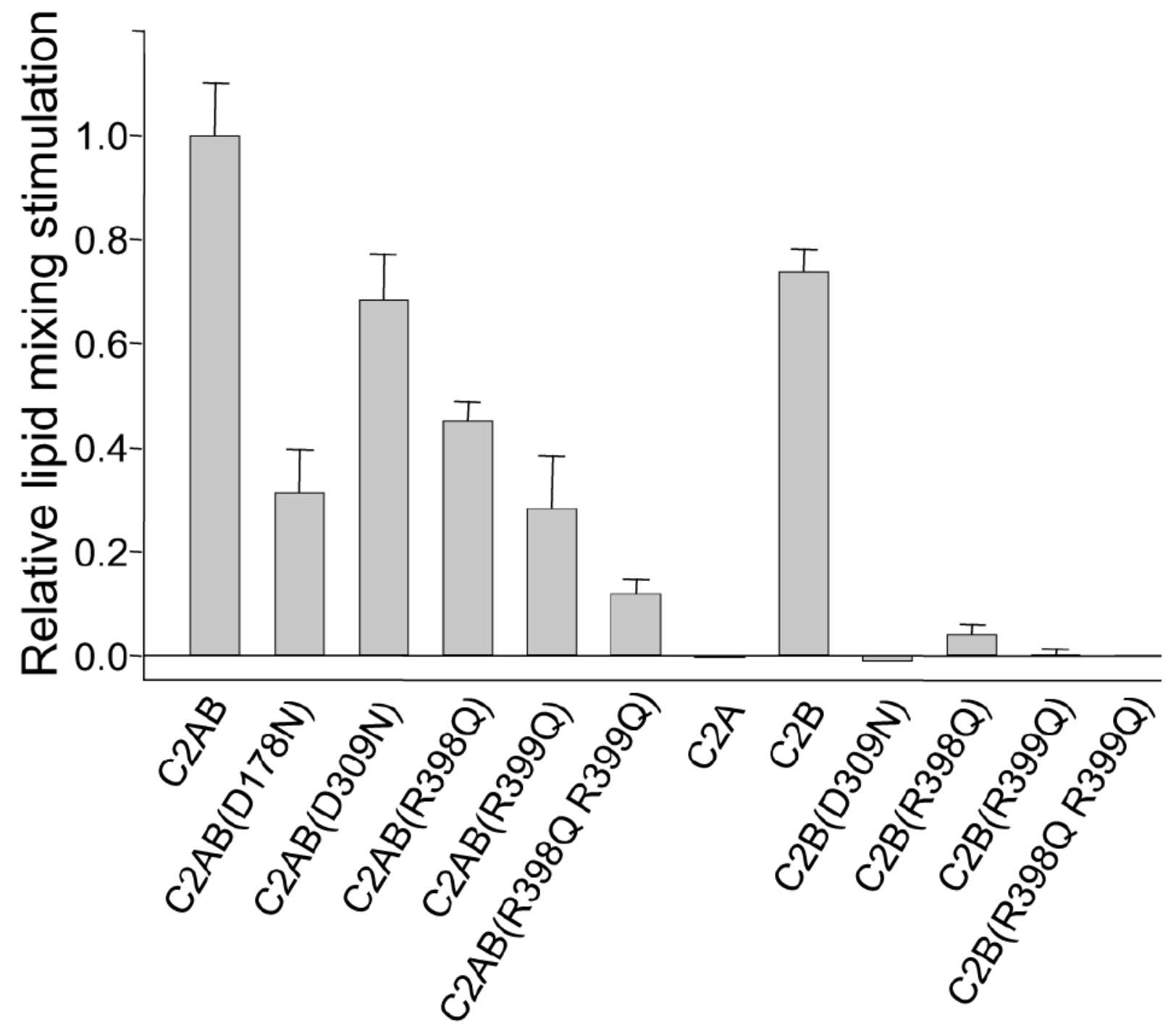

Figure 6.

Relative fusion stimulation activities of synaptotagmin-1 fragments. Lipid mixing assays analogous to those shown in Fig. 5 were performed for each synaptotagmin-1 fragment. The increase in $\mathrm{F} / \mathrm{F}_{0}$ during the 40 seconds following $\mathrm{Ca}^{2+}$ addition was measured, and the background $\mathrm{Ca}^{2+}$-independent lipid mixing was subtracted by linear extrapolation from the data acquired before $\mathrm{Ca}^{2+}$ addition. The resulting values were normalized to the average $\mathrm{F} / \mathrm{F}_{0}$ increase observed for the $\mathrm{WT} \mathrm{C}_{2} \mathrm{AB}$ fragment in parallel experiments with the same proteoliposome concentrations. Error bars show standard deviations from triplicate experiments. 

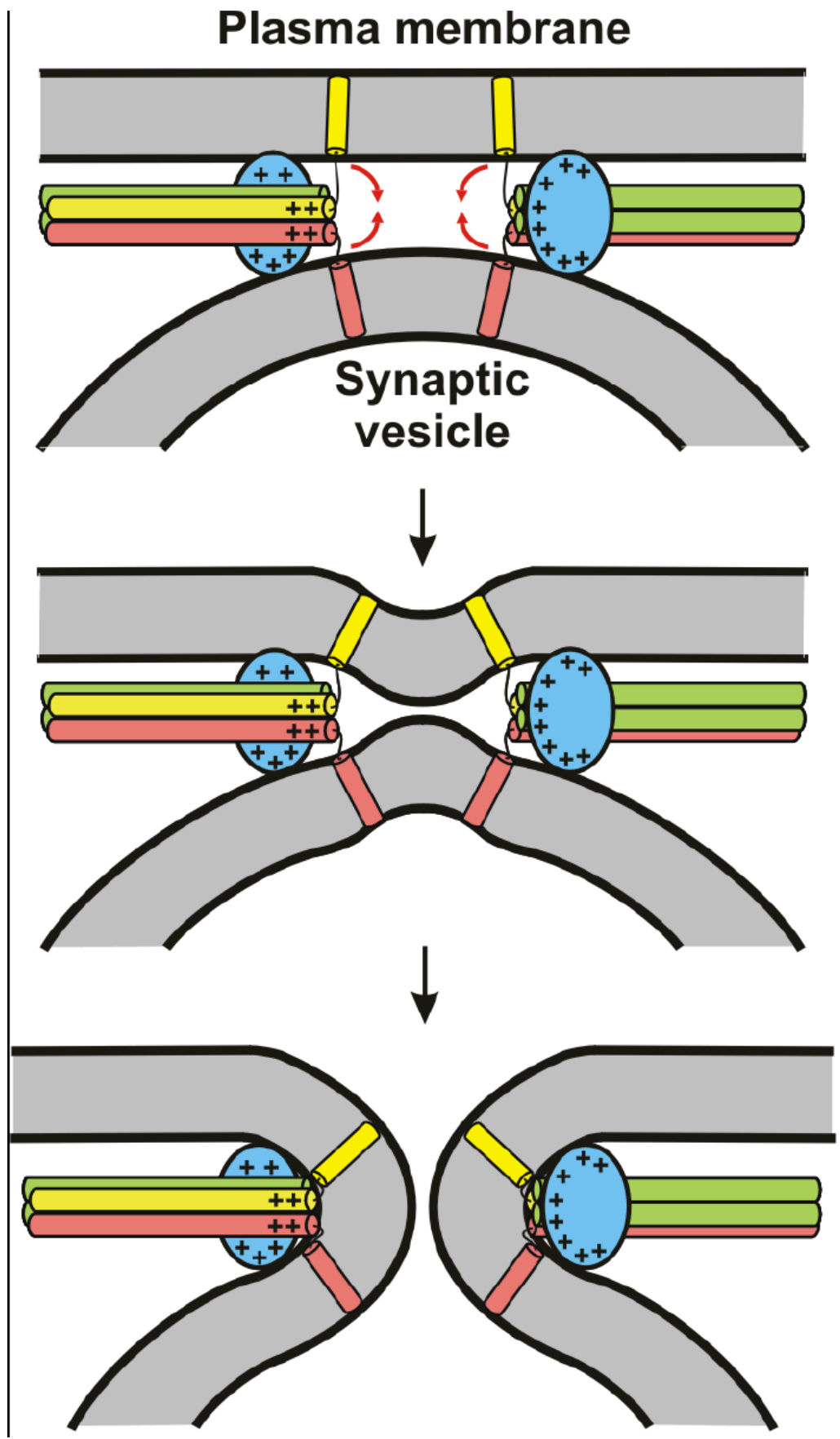

Figure 7.

Proposed mode of how the synaptotagmin- $1 \mathrm{C}_{2} \mathrm{~B}$ domain and the SNARE complex cooperate in $\mathrm{Ca}^{2+}$-triggered membrane fusion. The $\mathrm{C}_{2} \mathrm{~B}$ domain is colored in blue, syntaxin in yellow, SNAP-25 in green and synaptobrevin in pink. The $\mathrm{C}_{2} \mathrm{~A}$ domain (not shown for simplicity) is predicted to help in release by binding to one of the membranes, but could have additional roles that remain to be demonstrated. The model predicts that the $\mathrm{Ca}^{2+}$ binding loops at the top of the $\mathrm{C}_{2} \mathrm{~B}$ domain bind to one membrane, the bottom face to the other membrane, and the polybasic region to the SNARE complex (see Fig. 1a for the 
locations of these structural elements in the $\mathrm{C}_{2} \mathrm{~B}$ domain structure). In principle, the $\mathrm{Ca}^{2+}$ binding loops could act either on the vesicle or the plasma membrane. The + signs illustrate the abundance of positive charges in the $\mathrm{C}_{2} \mathrm{~B}$ domain and the $\mathrm{C}$-terminus of the SNARE complex [see ref. 17]. The red arrows in the top diagram indicate that these positive charges likely help to attract the lipids toward the center, inducing negative curvature on the membranes to initiate fusion. 